\title{
Intercultural Discourse, Critique, Emancipation and the Inclusion of the Other
}

\begin{abstract}
Fasil Merawi $^{1}$
Abstract

This paper critically engages contemporary discussions in intercultural philosophy and critical theory in light of achieving a profound critique of grand ideological schemes, propounding a model for an emancipatory praxis and the inclusion of the other in the dominant discourse. Intercultural philosophy tries to deconstruct the Eurocentrism of the philosophical tradition and in return introduces a reconstructive project centered on the embedded nature of cognition and the culturally oriented nature of philosophy. Critical social theory constitutes a critique of grand metaphysical systems that divorce theory from praxis and the transcendent from the transient. In return it tries to introduce an emancipatory praxis inspired by Hegelian-Marxism, is dialectical, reflexive, analyzes the contradictions of modernity and is interdisciplinary. Intercultural philosophy and critical social theory share a common interest in standing against grand metaphysical systems and centering on everyday centers of learning. Through such a critical exposition of the confines of intercultural philosophy and critical social theory, this paper argues that both approaches, (1) fail to go beyond the Eurocentric grand narrative of modernity that legitimizes Western ideology and is antithetical to the lived experiences of the other, (2) both approaches ultimately run into the problem of value incommensurability and (3) both approaches fail to introduce a quasi-transcendental foundation that both translate contending worldviews while simultaneously affirming the place of the other. Finally I will introduce an alternative model founded on the idea of multiple modernities which situates modernity as being situated in diverse cultural backgrounds.
\end{abstract}

Keywords: Otherness, Interculturality, Critique, Emancipation

\footnotetext{
${ }^{1}$ Lecturer, Department of Philosophy, Addis Ababa University
} 


\section{Introduction}

"How communication and understanding between philosophers is possible at all" Wimmer Franz Martin, Essays on Intercultural Philosophy

Humanity is currently embarking on the greatest stage of societal transformation exhibited in recent history. From the Syrian refugee crisis to migration in different corners of the world, heightened stage in the magnitude of fundamentalism, ethnicity and nationalism, to the attempt to go beyond free market capitalism, the world is truly witnessing a great societal transformation. Trying to demystify such a paradox, diverging interpretations of the nature of contemporary society and the quest for normativity and individuation have been proposed. Steunebrink and Van der Zweerde (2004) argue that in an advance of Huntington's thesis of the clash of civilizations, the Western model of political modernity is being challenged by Islamic fundamentalism. One as such should "consider Modernity to be a particular type of civilization, comprising a variable constellation of three major factors, namely civil society, religion, and the nation, against a specific cultural background, and within the framework of a political order (a polity) usually called 'the state'"(2004: I). Going beyond the clash of civilizations, others emphasize the crucial role played by risk as an organizing factor in social and political relations in contemporary society.

Here, Beck (1992) observes that in the current intellectual landscape, we are possessed with the 'post' thinking, seeking to go beyond material production, modernity and the values of enlightenment. Modernity's quest for progress and postmodernity's zeal for difference are both challenged. As such:

Those who now cling more tightly than ever to the Enlightenment with the premises of the nineteenth century against the onslaught of 'contemporary irrationality' are challenged every bit as decisively as those who would wash the whole project of modernity, along with its accompanying anomalies, down the river (1992: 10).

The dissatisfaction also extends to postmodernism. Harvey (1992) assumes that although initially postmodernism was conceived as a fashion of the day, it gradually gained momentum and redefined the whole of human relations and existence. In such a context, one needs, "to enquire more closely into the nature of postmodernism, not so much as a set of ideas but as a historical condition that required elucidation" (Ibid: $\mathrm{x}$ ). We need to approach postmodernism as such not based on a history of ideas but a radical transformation in our way of life and the creation of a space for authenticity.

For Treanor (2006) the emergence of non-comparable perspectives none of which is superior destroys the foundation for a common destiny, legitimacy and 
normativity. In such a world ", we are unable to confidently place the various others we encounter in a system that allows us to make accurate judgments about them"(2006:2).Undermining the entire foundation of human civilization, such opening up of a space encapsulates the inclusion of the other. Metaphysically, the other is conceived as something that is found outside of us whereas the ethical dimension constitutes finding a lasting solution and answer for the challenge of otherness. Thus:

In the most basic sense, the question of otherness asks us to consider what it means for something or someone to be other than the self; however, the question is more frequently asked in terms of our ability or inability to understand some particular example of otherness (Treanor 2006: 2).

For some like Anthony Giddens we are living in a world of globalization where modernity is elevated to a universal level and as such "rather than entering a period of post-modernity, we are moving into one in which the consequences of modernity are becoming more radicalized and universalized than before" (Giddens 1996: 3). The other is here treated as the South, the non-Western and the marginalized. For others like Lyotard we are in a postmodern world where visions of emancipation and utopia are abandoned for smaller narratives. Here postmodernism's, "principle is not the expert's homology but the inventor's paralogy" (Lyotard 1984: xxv). Going beyond such debate Treanor found an alternative approach that could be explained amongst others in Emmanuel Levinas' departure that treats the other as unique and not a thing. Here, "rather than seeking to eliminate otherness by grasping it and analyzing it in order to reduce it to a known quantity, his philosophy seeks to preserve the otherness of the other and to respect the difference that distinguishes the other from the self" (Treanor 2006: 5). In this paper, through an analysis of intercultural philosophy and critical theory, I will argue that although conceptions of critique, emancipation and otherness find expression in such approaches, still both run into the problem of eurocentrism and incommensurability.

In section one; I will try to critically expose the dynamism between migration, intercultural discourse and the quest for inclusive participation. This is followed by the introduction of intercultural philosophy as an orientation that tries to critique Western ideology, envisages model of emancipation and proposes an inclusion of the other in mainstream discourse, in section two. In section three, the reflexivity and dialogical nature of critical social theory is situated in terms of introducing a critique of ideology, immanent critique and emancipation as the goal of critical praxis. Finally, in section four, a critique of intercultural philosophy and critical theory is proposed in terms of a critique of eurocentrism, the challenge of 
incommensurability and the notion of multiple modernities as an attempt to create a space for the participation of cultural programs in the discourse of modernity.

\section{Globalization, Intercultural Discourse and the Inclusion of the other}

In the world of globalization, the interaction amongst nations, cultures and communities is being furthered by diverse factors ranging from the latest developments in science and technology, the culture industry, public spheres and the media, liberalization policies, discursive practices and migration. Particularly, due to migration, dynamism is taking place amongst individuals and cultures, and one daily comes across the other and contemplates otherness. Here for Epstein and Gang (2010) in the dynamics between migration and cultural participation amongst individuals, fusion into others and total seclusion are the two dominant responses. Furthermore, amongst others, one feature of migration on a global scale is migrants selecting particular destination and also settling alongside particular identities. One sees "the clustering of immigrants in ethnic communities" (2010:2).

\section{Migration and the Dynamics of Intercultural Discourse}

Currently one witnesses, a south-north migration fueled by primarily political factors, economic needs and also a south-south migration relying on values, cultures, linguistic reasons and other factors. The most important factor that is driving the migration dynamics is political instability. The masses resort to migration out of the need to escape dictatorial regimes, suppression of human rights and exploitation in their respective nations. Some of the political circumstances serving as causes for migration are, "political instability, sudden and dramatic regime changes, ethnic tensions and confrontations, and proxy civil wars" (Agadjanian 2008: 414).There are eight main gateways that characterize the current international migration for Solimano (2010). These include the difficulty of arriving at mutual understanding on the crisis and the simultaneous economic growth and disparity initiated by such migration. As such, "a main concern of current globalization is the contrasting disparities in economic levels, living standards and economic potentials across nations"(2010: 10).The migration dynamics also consists of prioritizing material growth over intrinsic values, and migration being more accessible to the educated than the laboring masses.

in such a world of migration, intercultural discourse and communication is regarded as a way of identifying underlying structural patterns, proposing dialogical encounters and proposing solutions to cross cutting issues like economic development, terrorism and destruction of the environment. For Paulston et al. (2012) in attempts to understand intercultural, there is a need to engender a transition from an essentialist conception that views cultures as fixed, natural, unchanging and metaphysically different into a discursive one that emphasizes cultures as created, symbolizations and formations in our language, imaginations 
and perceptions. As such, "whether culture is viewed as nation, as ethnicity, as faith, as gender, or as sexuality, all these cultures have one thing in common: they are imagined communities" (2012: 5).

For Monaghan (2012) initially the study of intercultural communication assumed the form of teaching foreign language to Americans but eventually branched out into the analysis and comparison of languages from the orient with the occident. As such:

While intercultural communication began as exploration of the practical topic of how to teach people to communicate well in contexts where they were interacting with people from other cultures, discourse analysis's roots were in the general exploration of the relationship between language and culture. (Ibid: 22-23)

Emphasizing discourse analysis in communication and symbolic ways of life, currently the interaction between the study of language across cultures and its discursive formation are emphasized. By situating communication in society, values, power relations and material production, there is an attempt to envisage a dialogical encounter amongst participants.

\section{The Emergence of Otherness and the Other}

For Rüsen (2004) our historical encounters of the West are permeated by the ethnocentric tendency to prioritize one's self and culture over others. As such, "much international and intercultural discourse about historiography is influenced by a way of historical thinking deeply rooted in human historical consciousness and that works throughout all cultures and in all times: ethnocentrism"(Ibid: 118). The solution, in return, resides in conceiving development of societies as situated, opening up of a space for the unique self and seeing multifaceted experience as an alternative.

Otherness presupposes an ontological separation of others from one's world and practical relations of asymmetry in the world. This for Martinez (2015) concentrates on the division between groups, the powerful and the powerless. Still, going beyond the critique of the other as a response to existing relations, the genuine self, needs to seek not absolute freedom but a space to articulate its nature. Accordingly, "the human ability to other allows for detachment to happen in social and personal relationship, which affects the self-perception and identity" (Ibid: 153). Recognizing the relation of interdependence between the dominant self and its other, two major impositions on the self must be affirmed. These constitute, societal forces having an impact on class divisions, ethnic lines and constitution of the individual psyche amongst others and relational ones encompassing our communion with others presiding over daily discourse. Thus, "the authentic self is 
one who can identify the social impositions, which oppress or privilege oneself and recognize the balance of all social roles in relation to personal experience and formation"(Ibid: 158).

The notion of the other or otherness cannot be analyzed without affirming its intrinsic relation to the problem of evil. In return, the problem of evil could be understood as having a relation to language, individuation, power relations, normative presuppositions, conceptions of the world and ultimate reality. Schrag (2006) argues that moral evil could be inflicted once we conceive others as belonging outside one's realm and thereby turning the other into evil. Here, "estrangement as a coefficient of otherness, otherness under the conditions of estrangement, the other as stranger or alien, provides the mark of the separateness of finitude somehow gone wrong" (Ibid: 151). In such a context, one needs to probe the issue, could the narrative of the modern state capture the historical context in which the other emerges in our world? On the contrary, Schrag argues that otherness and evil would still grow on divisions fostered by conflicting cultures and civilizations. Here, going beyond philosophy and politics, a conception of gift that expects nothing in return in opposition to the politics of friendship is the only viable solution. As such "an economic gift of love at once transforms the restricted notion of friendship into a universal fraternity and sorority and sets the condition for the requirement to love even one's enemies" (Schrag, 2006: 154).

Staszak (2008) assumed that the other refers to an inferior that is excluded from proper culture; othering refers to the systematic creation of an outside to establish relations of hierarchy while otherness consists of the features of the excluded. Conceptually, the notion of otherness still became manifest geographically where one gazes at the difference of others in their spatio-temporal location. The other as such is not full in its own lifeworld, but only emerges in a reference to the dominant self and culture. Based on this, "otherness and identity are two inseparable sides of the same coin. The other only exists relative to the self, and vice versa" (2008: 2). The Western othering of others is unique since it is informed by the quest for logical identity and dichotomous operations and is also practically instilled by Western imperialism. Generally, "all societies create the self and the other with their own set of categories" (Ibid: 3).Here as Lipner (1993) observes, the awareness of the existence of different identities, value systems and forms of life existed throughout the history of philosophy. Still, what is striking about the current world is affirming such challenge and even seeing it as a foundation for pluralism and difference. Thus, "truth is widely perceived today as entailing a contextual awareness so that philosophies reducing truth to the realm of atomic propositions fail to convince" (Ibid: 154).

Having discussed the mutual relationship which exists between migration, intercultural discourse and otherness, I now try to introduce a philosophical 
response to cultural diversity and the need to introduce a pluralistic element in the philosophical tradition under the orientation of intercultural philosophy.

\section{Intercultural Praxis, Critique of Eurocentrism and the Inclusion of the Other}

For Shen (2011) in the globalized world, comparative and intercultural explorations are animated by a need to go beyond one's surroundings and the need to reevaluate the credibility of one's values upon encountering the existence of others. Here, "comparative studies in philosophy, religion, social sciences and culture, etc., always presuppose and indeed involve, on the one hand, the existence of many others and the act of going outside of oneself to many others, and, on the other hand, a deeper understanding of one's true self and potentiality, and the precious values accumulated in one's own tradition" (Shen 2011: 2). Shen assumes that multiculturalism should be augmented by an intercultural drive that initiates dialogical encounters and understands the diverse situated manifestations of a cultural space. Here, "especially in this time of radical change, any philosophy/religion capable of facing this challenge has to include in itself an intercultural dimension" (Ibid: 3).The goal resides in revolving between particularities and existing alongside one another, progress and genealogy amongst cultures.

\section{Wimmer, Intercultural communication and Polylogical Encounters}

Even before the development of intercultural philosophy, the human sciences always reserved a place for a possible encounter amongst cultures. Still, without succumbing to mere relativism and dictating all philosophy by value-laden orientations, intercultural philosophy demonstrates the dialectic between the universal and the particular. Accordingly, "the fact that every philosophical tradition has its own cultural background must not lead necessarily to a determinism and cultural relativism" (Kaltenbacher 2014: 40). In such intercultural ventures the analysis of the past, existing relations and structures must be coupled with different dimensions of understanding, theoretical constructs and knowledge of the environment. And as such, "intercultural" is the proper term because "it carries not just the in-between, but the active sense of interaction, confrontation, and even conflict" (Liu 2013: 194).

For the possibility of intercultural philosophy, a place for translation amongst contending perspectives and diverse philosophical traditions must be available. As such, "pre-empting an account of intercultural philosophy, if it is to be possible at all, has to be assumed that different cultures, languages, traditions, religions, values, and practices are not incommensurable" (Ozoliņ̌s 2013: 19). Ozoliņš argues that material dominance, availability of resources and other factors negatively 
influence the spirit of intercultural encounters thereby making it one sided. In such a context, "we do not have intercultural philosophy, but rather, we find that we inter cultural philosophy, that is, we bury the culturally distinct philosophy of the smaller country" (Ozoliňš, 2013: 22). Since no one could ever resolve issues regarding philosophical methodology and goals, it is better to engage in different issues that enrich the human experience and articulate diverse points of discussion.

The intellectual challenge in the world of globalization constitutes the need to account for the proliferation of diverse philosophical outlooks. Thus, "amidst a period of globalization of many aspects of human life, the problem now arises, whether there will be one single form of method of philosophy in the future" (Wimmer 2002: 7). For Wimmer, one could unearth diverse empirical and conceptual tools that demonstrate what diverse cultures contributed to the philosophical tradition. In proposing to answer the question how is philosophy possible in a world of seemingly incommensurable modalities, Wimmer tries to consider "how communication and understanding between philosophers is possible at all" (Ibid: 9). As part of such an attempt, there is a need to critique Western historiography, identify the structural element in philosophical claims and the limits of ethnophilosophy as a resolution to the objectivism/relativism dichotomy.

According to Wimmer, there is an attempt to relegate non-Western philosophy to the status of tradition and imitation thereby situating philosophy as the logic of Western culture and the most refined and qualitative Western product. Although occasional mentions of Confucianism and Islamic philosophy are made, African philosophy is treated as part of the critique of Western cultural practices. Here, "the preconditions and the functions of the delimitations against the foreign have to be analyzed" (Ibid: 12). The limitations of a common translation are identified by Kwasi Wiredu's analysis of conceptual decolonization although it is not only modern Western and African traditional, but all languages involved that must be analyzed. As such "to decolonize so many concepts by commenting and reviewing metropolitan languages with the means of very different languages will not be sufficient" (Ibid: 14).

One major challenge in intercultural philosophy arises from the fact that claims in language are particular, nationalistic, and stand against universalism and objectivity. For Wimmer, the cultural and transient is attractive to the postmodern although it also levels the distinction between reason and emotion, philosophy and literature. Amongst others, one witnesses that the critique of ideology itself becomes ideological in ethnophilosophy's zeal to assert the supremacy of one's cultural background. As part of the solution, Wimmer proposes affirming the existence of different voices and cultural constructs, seeking shared grounds and thinking of philosophical traditions in the continuum between culture and universality. Such a quest "will be a continuation of the project of European 
enlightenment with different means, not only by relying on a unique method of science, but by creating a polylogue of traditions" (Ibid: 25).

In considering different modes of interaction amongst philosophical traditions, Wimmer analyzes a stage where one model is superior, another where, one is imitating the other model, mutually incompatible centers and finally a polylogue where learning takes place amongst cultures. Only considering the possibility of a polylogue from a logical and not a factual standpoint, Wimmer argues that in reality equality is unattainable and there will always be a unique other. Thus, "it is important to ask whether such an ideal can serve as a regulative idea for practicing philosophy on a global scale" (Ibid: 29). Different communities of the world continually strive for recognition by others and seek to exert their dominance in the world of meaning and technical mastery.

In today's world of societal change and transformations, Wimmer exposes diverse ways of holding onto the past. Traditionalism resides in a zeal for the perfect past and origin which is lost. Any dynamism here is regarded as corruptive and a form of degeneration. Here, "whoever is controlling the calendar is controlling an important part of the self-interpretation of the collective" (Ibid: 41). The conception of a culture could also be utopian, evolutionist and pluralistic. In utopianism, there is an attempt to posit a perfect ideal in the future, while evolutionism thrives on the idea of abandoning the past and future orientations for gradual change and transition. Furthermore, pluri-polar identity grows on the back of an eclectic approach and appropriation of diversity. As such, "it is surprising that nowhere we find anything like a pre natural human being (Ibid: 5).

\section{Mall, Postmodernity and the Celebration of Difference}

For another major advocate of intercultural philosophy, Mall (2000) while transculturality emphasizes going beyond particular sites and cultures into the global, interculturality centers on context tied claims to universality, the embedded nature of cognition and the role of cultures as cores for universal claims to truth. Going beyond relativism's affirmation of separated sites of knowledge and universalism's ideal of truth divorced from contexts; interculturality resides in the dialectic between the universal and the particular. As such, "the tendency to absolutize oneself exclusively ultimately leads to deadlock, for different absolute positions, when confronted with one another, automatically relativize themselves" (2000: 3). Mall believes that intercultural philosophy shouldn't be understood as a branch of philosophy, a philosophical tradition, mere collection of approaches, recourse to the past or an aesthetic form of critique. Thus, "intercultural philosophy is the name of an attitude for the deep philosophical conviction that the one philosophia perennis is the exclusive possession of no one particular philosophical tradition, be it Western or non-Western" (Ibid: 37). 
Within the postmodern discourse, Mall identifies a strong version which resides in the relativization of all claims to truth and a weak one that sees culture as a manifestation of plurality, seeks to identify shared spaces and promotes encounters amongst cultures. For Mall, the weak version of postmodernity just like interculturality, supports the situated nature of philosophical traditions without failing either to the relativist or objectivist positions. Such a weak version "tries to work out overlapping amongst cultures, philosophies, and religions without, of course, denying, reducing, or explaining away the presence of diversity" (Ibid: 40). Mall is also critical of Habermas' theory of communication which, "makes itself immune to all of the different social and manipulative factors by constructing an ideal speech situation" (Ibid: 39). Furthermore, it is practically difficult to find an empirical ground for such a theory of communication.

McGhee (2011) considers both classical philosophy and comparative philosophy as being engaged in an esoteric quest for wisdom. Based on this, "the origins of philosophical estrangement from the world must lie in the exposure to its cynical view of knowledge and opinion as instruments of policy and power" (Ibid: 26). Surpassing such comparative ventures, polylogical dynamism amongst multiple partners is introduced in intercultural philosophy. The idea of a polylogue for Chen (2010) underscores the multiple encounters existing in our world and the fact that our sense of self is formed in our interaction with others. Based on this, it tries to expand the centers of truth from two to multiple partners. Dialogue is useful as a critical encounter amongst participants, still a polylogue resonates more with the diversity of values and ways of life in our world. As such, "accentuating the importance of the polylogue does not indicate the dialogue to be an obsolete form of communication" (Ibid: 54).

Issues like defining the nature of philosophy, what animates philosophy and its dynamism with other forms of knowledge and everyday life are crucial challenges to intercultural philosophy. It is presumed that "what the project of intercultural philosophy brings to philosophies characteristic of particular cultures and traditions, then, is - novelty that incites development" (Sweet 2014: 186-187). Still, to what extent did intercultural philosophy successfully realize the participation of African and other cultures in the philosophical tradition? The intercultural orientation envisages a critique of hierarchical relations of cultures seeking an alternative ideal in a process of mutual learning. Accordingly, "intercultural philosophy is an orientation that sees philosophy as being culturally bound, but affirms that communication is still possible between those of different philosophical backgrounds"(Olu-Jacob 2014: 107).

Bekele Gutema (2015) supports such a line of reasoning in conceiving philosophy as a way in which a culture critically articulates its existence and also engages in a re-examination of cultural values with the power of rationality being situated in the local context. Here, African philosophy as an enterprise constitutes 
various strands ranging from the oral to the written, and the traditional to the postcolonial one which is "constituted by a wide range of philosophical texts in domains such as ethnophilosophy, philosophic sagacity, and social and political philosophy"(2015: 139-140). Besides offering a critique of Western knowledge systems, African philosophy could also contribute a unique philosophical response grounded on the African soil and inspired by existing conditions in Africa. Here a parallel is drawn between African philosophy and intercultural approaches since the conception of situated cultures striving for universality plays a dynamic role in both perspectives. Using Eze's recent argument in his On Reason, Rationality in a World of Cultural Conflict and Racism (2008), Bekele argues that philosophy always originates in specific context and is temporal regardless of the particular form it assumes. Currently due to limitations in the mode of presentation and not properly being mainstreamed into philosophical traditions, the intercultural dimension of African philosophy needs to be further tuned. As such, "although intercultural philosophy is taking root, an intercultural approach to African philosophy has not yet progressed as far as it should have. The contemporary importance of intercultural philosophy renders the use of an intercultural approach both necessary and fruitful" (Ibid 153).

\section{Critical Theory and Immanent Critique as Emancipatory Praxis}

Whereas the proponents of intercultural philosophy propagated the cultural inputs of a given culture serving as the background of a philosophical tradition and universality as the general horizon, critical theory emerged in the background of the catastrophes of WWI and the need for an intellectual resolution that interferes in existing reality. In this section I will try to map out alternative conceptions of critical theory focusing on the themes of critique, emancipation and otherness.

\section{The Genesis of Critical Theory and the Notion of Emancipatory Praxis}

As Rush (2004) argues, critical theory's origin could be situated in the attempt to dissociate oneself from the social sciences and hermeneutic studies that try to work out the implications of German philosophy to philosophy of history. Critical theory on the one hand has a Marxist origin in trying to demystify the agents of exploitation so that existing relations will be revolutionized. On the other hand, it also inherited the Kantian notion of critical philosophy in focusing on the object of critique and the limitations of critique itself. As such, critical theory tries to "explicate conditions upon rationality and regards this task as implicating its assessment of its own rational limitations" (2004: 10). Furthermore, critical theorists also borrowed the notion of alienation which was first introduced by Hegel and later incorporated into Karl Marx's dialectics to understand how "humanity is estranged from its normative ends and its creations escape its 
conscious control" (Bronner 2011: 37). Critical theory's appropriation of Hegel was met with ambivalence. While critical theorists reserved the Hegelian quest for an objective model of emancipation, they still identified the subject of analysis not as the absolute spirit but the finite, corporeal and transient. As such, "Critical theorists learned to interpret the particular with an eye on the totality. The moment of freedom appeared in the demand for recognition by the enslaved and the exploited" (Ibid: 2).

Amongst the various proponents of critical theory, Horkheimer believed that whereas traditional theory is contemplative, reductionist and universalizing, critical theory couples theory and praxis, and is concerned with both critique and emancipation. Adorno also assumed that speculative philosophy ought to be replaced with a materialistic and historical analysis that traces the genesis of existing relations. Here, "such critique is unending, at least in the sense that the theorist always operates under the assumption that further critique is possible" (Rush 2004: 31). According to Feenberg (1981), the foundational blocks of critical social theory could be understood in Marx's and Lukas' attempts to lay down an account of a philosophy of praxis that goes beyond scientific socialism's essence of strict administrative bureaucracy and instead emphasize the humanistic and emancipatory aspects of Marxism. Such an insistence is directly informed by the mind/body dualism. Thus, "ever since Descartes distinguished the two substances, philosophy and life had become more and more sharply sundered in accordance with this distinction" (Ibid: 5).

Being inspired by Ulrich Beck's Risk Society, contemporary critical theory is in part an attempt to address the notion of reality as a social construct and human relations as the driving factor for construction of reality, amalgamation of knowledge and practice plus analyzing the danger of scientific and technological rationality. Here, one needs to affirm, "The necessary involvement of a sense of 'construction in the configuration of risk-perception" (Adam and Loon 2005: 2). For Delanty (2009) critical social theory must be grounded on a cosmopolitanism that overcomes the limits of the globalization debate by encompassing an analysis of societal transformation with power relations, cultural values and overcoming eurocentrism and also empirical studies with normative presuppositions. As such, "the idea of a critical cosmopolitanism is relevant to the renewal of critical theory in its traditional concern with the critique of social reality and the search for immanent transcendence, a concept that lies at the core of critical theory"(2009: 2).

Whereas WWI resulted in the emergence of critical theory, the aftermath of the great depression led into its popularization in America. Particularly for Piccone (1976), the rise of Nazism and the tragedy of the holocaust casted doubt on critical theorist's faith in reason, progress and human emancipation. As such, "it was clear that Nazism was a reversion to barbarism, and moreover, a monumental default on all the emancipatory promises of western civilization" (Ibid: 101). Resisting grand 
metaphysical systems, critical theory underscored the interplay between human cognition and human interests. Thus, "by contrast, critique that is immanent or indwelling presupposes the criteria that are present in the situation, criteria by which the situation judges itself, and asks whether it meets its own raison d'être" (How 2003: 4-5).

Antonio (1983), remarks that the popularization of critical theory in America arose from its systematic analysis of the pitfalls of both socialism and capitalism and combination of the analysis of values and material relations, in a general model of emancipation. Attempts were made to figure out the opposition between scientific socialism of Marxism and revolutionary praxis and critical Marxist advocacy of human emancipation and their influences on critical theory. As such, "scientific Marxism stresses the need for party organization to guide a proletarian revolution - in contrast, critical Marxism abandons concepts of bureaucratic party organization and historically inevitability for themes of emancipatory consciousness, mass action and revolutionary spontaneity"(Ibid 1983: 327). Besides its popularization in different parts of the world, critical theory is also characterized by the dominance of individual thinkers who set its foundations in different forms of emancipatory practice.

\section{From a Critique of Ideology to a Totalized Critique of Rationalism}

One of the major advocates of earlier critical theory is Herbert Marcuse. For Kellner (2001) Marcuse's critical theory is essentially an attempt to unravel the metaphysical foundations of Marxism, enrich it with the analysis of the subjective world of the concrete individual and highlight the maximal role of communal, normative and individual quest alongside power relations and material production. Furthermore, Marcuse, "believed that Marxism neglected the problem of the individual and throughout his life was concerned with personal liberation and happiness, in addition to social transformation" (Ibid: 3). Marcuse, using a Freudian analysis arrives at the observation that the development of technical progress, human societies, material production and instrumental rationality stood against the freedom of the subject. Here, "the methodical sacrifice of libido, its rigidly enforced deflection to socially useful activities and expressions, is culture" (1974: 3).

For Horkheimer (2002) the conventional conception of theory focuses on the strict compartmentalization of research domains, objectivity of researchers, development of abstract theories and fetishizing concrete human relations as if they are natural and universal facts. Accordingly, "the traditional idea of theory is based on scientific activity as carried on within the division of labor at a particular stage in the latter's development (2002: 197). As Hoy and McCarthy see it, especially for Horkheimer, critical theory acknowledges how knowledge is 
produced consciously in a specific cultural context, and challenges, the view of theory as value free and devoid of any interests. Hence, for Hoy and McCarthy,

unlike 'traditional theory', then, critical social theory takes as topics of investigation the reflexivity of social research, the division of labor-including scientific and scholarly labor- in which it is carried on, and its social functions... It reflects, in particular, on the contexts of its own genesis and application, that is, on its own embeddness in the social matrix out of which it arises and within which it will find its uses (1994: 15).

In Horkehimer and Adorno's Dialectic of Enlightenment one observes a shift in critical theory from the critique of ideology to a critique of reason as such. In mythical thinking, what is emphasized is how things stand in an intrinsic relation to the whole. In this context, "only demythologization dispels this enchantment... the process of enlightenment leads to the desocialization of nature and the denaturalization of the human world" (Habermas 1987: 115). In 'demythologization', the role of tradition is undermined, norms, conventions and rules are replaced by contestable claims to truth instead of a unitary whole, the world becomes differentiated into that of objects, norms and subjective one.

As Habermas tries to show in his critique of Horkheimer and Adorno, it is only in the context of the rise of the value spheres of science, morality and laws and art replacing the power of traditions and myths, that one could make a critique of ideology. Hence, "if one describes the process suspended between myth and enlightenment in this way, as the formation of a decentered understanding of the world, the place where the procedure of ideology critique enters into this drama can also be specified" (Habermas 1987: 115). Habermas marks, the critique of ideology as a moment of reflexivity in modernity. This changes, when reason itself is questioned or the issue whether reason itself can liberate humanity or when the aporia of what it means to reason are emphasized. The analysis turned from what reason serves in society, to what reason has led humanity in general. Hence, Horkheimer and Adorno; "pushed for a radicalization and self-over-coming of ideology critique, which was supposed to enlighten the Enlightenment about itself" (Ibid: 118).

\section{Habermas, the Communicative Paradigm and the Inclusion of the Other}

Currently the tradition of critical theory finds voice in Habermas' discourse of modernity that attempts to rescue the project of modernity from the postmodernist critical theories of Foucault, Derrida and Lyotard. For Coole (1997) Habermas' notion of otherness and alterity is part of his critique of postmodernism. Habermas construes the other not as ontologically different but as an equal participant in 
everyday intersubjective validation. Thus, Habermas "is unable to attribute any emancipatory potential to alterity, or otherness, however, because his basic ideas concerning communicative reason and an emancipatory project of modernity are predicated on its exclusion" (1997: 221). Habermas attempts to reconstruct the Kantian spheres of reason and Hegelian element of reason progressing in history through the reflexivity of language. In the process, he denies alterity and otherness diversely manifested in terms of the Dionysian motif, Being, unrestrained will, absolute subjectivity or disciplinary matrix. As such "Habermas' antipathy towards poststructuralism thus rests on his denial of any emancipatory role to alterity" (Ibid: 222). Habermas has further articulated the place of otherness and difference in his ideas on human rights as encapsulating both normative grounds as well as legal guidelines. Thus, "he argues that human rights are not simply moral rights, but are Janus-faced with one side related to law and the other to morality" (Flynn 2003: 431).

Habermas' solution to the issues of alterity and otherness, tries to go beyond two major extremes. First of all, tolerance is seen as a rule describing what is intolerable, and intolerance leading to tolerance. Secondly, we tolerate what we don't accept and consent with. As such, "the two aspects of the paradox of tolerance - arbitrariness and paternalism-arise from the way in which the norms of tolerance are decided and justified" (Thomassen 2006: 440). The possibility of inclusion and tolerance is made possible by two-level integration in politics and ethics. In the rationalization of the life world, the ethical realm deals with the interests of the subject and the moral with collectivities. Such a process is democratic in utilizing the input of everyday individual and universalistic in realizing the participation of all individuals ideally. As Thomassen remarks, the fact that normative principles originate within a given context inclines the nature of tolerance and otherness more towards the individual and the ethical perspective. Habermas imposes an idealized conception of rationality to realize symmetry in the politics of tolerance and an alternative model of tolerance and otherness where "the condition of possibility of inclusion and tolerance is simultaneously their limit" (Ibid: 447).

Cronin and Greiff (1998) argue that Habermas' quest for tolerance, recognition, and otherness form an integral aspect of his political philosophy. Such a philosophical deliberation recognizes the enforcing and regulative mechanism of legal systems on one hand and their quest for rationality and legitimation on the other hand. Here one asks, "What is the ground of the validity of the principle of justice that form the core of modern democratic constitutions?"(1998: viii) Habermas' conception of otherness just like Rawls starts off by affirming the existence of diversity in the contemporary world. Still, whereas Rawls is skeptical towards reaching agreement, Habermas assumes that everyday validity claims the 
force of the better argument and the universal validity of claims lays the foundation for universalistic horizons and public spheres of truth.

As Habermas (1998) remarks in his The Inclusion of the other morality must be founded in rationality, intersubjective recognition and validity. By continual reflection, identities are created and recreated in a transitory manner. Accordingly, "The "inclusion of the other" means rather that the boundaries of the community are open for all, also and especially for those who are strangers to one another and want to remain strangers" (Ibid: xxxvi). Soon recognizing pluralistic conceptions of the good and the good life, individuals, communities and identities will engage in a process of legitimation through the force of the better argument. Here, "in the absence of a substantive agreement on particular norms, the participants must now rely on the neutral fact that each of them participates in some communicative form of life which is structured by linguistically mediated understanding "(Ibid: 40).

\section{Incommensurability, Critique of Eurocentrism and Multiple Modernities}

In the previous sections, I tried to analyze the quest for the other in the world of globalization, in the interplay between universality and particular cultures and otherness as an integral aspect of today's democratic societies. Here, I will articulate my critique of intercultural philosophy and critical theory centered on themes of eurocentrism and incommensurability and situating the notion of multiple modernities as an alternative paradigm for the recognition of otherness.

\section{Eurocentrism and the Quest for the Other}

The approaches of intercultural philosophy and critical theory are founded on the attempt to develop sensitivity to relations of asymmetry through a critique of a metaphysical thinking that grounds existing human relations. Despite such attempts, both approaches end up implicitly affirming the superiority of Western culture. Intercultural philosophy affirms eurocentrism in following the colonial sciences that create a false notion of otherness, using Western conceptual distinctions to analyze intercultural encounters and failing to interrogate the foundations of the present global order in relations of exploitation and asymmetry. Critical theory also succumbs to eurocentrism in limiting its analysis of critique and emancipation to the contradictions of capitalistic mode of production within the Western soil, failing to interrogate the foundation of Western modernity in colonialism and imperialism.

Intercultural philosophy systematically creates the other that has so far been excluded from mainstream discourse, which is negated by Western ideology and is unique in its culture, and ways of life. Here just like the colonial sciences, intercultural philosophy also operates within the distinction between modern and traditional, individualistic and communal, objectifying and affirming oneness with 
nature, written and oral to establish the unique position of the other in intercultural discourse. Upon recognition of the role of the sciences in justifying colonialism, colonial science for some refers to the body of knowledge produced in the age of colonialism. For others it refers to the type of scientific enquiry carried out within the colonies. Amongst others different disciplines like anthropology and archaeology have been charged with propagating eurocentrism and facilitating the negation of the other.

As Pels puts it, anthropology as a study that emerged within the colonial discourse and its practitioners are still trying to dissociate themselves from such a colonial legacy. "The discipline descends from and is still struggling with techniques of observation and control that emerged from the colonial dialectic of Western governmentality" (1997: 164). Pels adds that some anthropologists see colonialism as an integral aspect of history, others perceive colonialism as a procedure which requires subjugation for the advancement of societies, while still others see colonialism as a manifestation of the fact that societies progress through adaptation. Going beyond anthropology Sheperd (2002) identifies the colonial spirit of marginalization in the introduction of archaeology in Africa. Diversely phrased in terms of Africa as the cradle of humanity, precursor to human civilizations, the archaeological studies neglect genuine diversity and end up establishing Europe's quest for self-affirmation. Thus, "such sites of political identification span the range of issues of race, culture, and identity, and have placed archaeologically constructed knowledge in relation to phenomena of colonialism, nationalism, apartheid, slavery, and neocolonialism" (Sheperd 2002: 189). Intercultural philosophy just like the colonial sciences, pictures nonwestern cultures as exotic worlds waiting to be explored and the seats of difference that represent the other of the Western world.

According to Blocker (1999), both the word "philosophy" and philosophy as an intellectual exercise are normatively oriented in their nature. Although, to avoid bias and prejudice in presenting the views of others, the best way is usually seen as trying to expound the thoughts and philosophies of others on "their terms", this proves problematic for a number of reasons. One, getting sufficient access about the thoughts of others is difficult. Two, even if we could gather vast information, still understanding goes beyond awareness to things like integration and becoming part of the other. Three, even if we succeed in becoming part of others, still using our own categories, interests, problematic and concepts is needed.

In exposing the eurocentrism of critical theory, Kaye and Strath (2000) argue that although, modernity propounded a model of rationality driving human progress and history, such a quest was coupled with ideology and degenerated into relations of destruction. The proclaimed subjective rationality, empirical sciences and technological advancements also facilitated genocide, destruction of human life and racism. Because of this, "social criticism and the belief in progress through 
human action proved to be an explosive mixture insofar as they took the world to the brink of atomic war which challenged the right to life itself" (Kaye and Strath 2000: 11). Positing a contemplative and idealized rationality against mythology and emotions, modernity and enlightenment introduced categories, orders and classifications that subjugated the other. Thus, "abstraction and classification effaced the face, when the owner of a category was transformed from being an individual to a specimen" (Ibid: 15).

Ferrara (2002) proposes a thesis of authenticity that goes beyond the modern vs. postmodern debate in critical theory. On the one hand, using intersubjective validation as a foundation, it is argued that the limitations of modernity and the critical project reside not in material foundations, but philosophical conceptualizations of idealist metaphysics and philosophy of the subject. On the other hand, abandoning modernity as a lost cause, a postmodern world is inaugurated where the center cannot hold and claims to truth are concealed in claims to power and meaning. Here, "the alternative of bringing the project of modernity to completion versus abandoning it altogether, however, is somehow too crude and even misleading" (2002: 149). Introducing a third approach, Ferrara focused on going beyond the dichotomous relations between cognition and praxis and the notions of postcolonial enlightenment and postcolonial critical theory.

In the eyes of Festa and Carey (2009) postcolonial enlightenment requires an epistemological restructuring of Western cultures' perception towards others, and also a moral dimension that furthers genuine relations of symmetry. This is also founded on the recognition that, "the introduction of postcolonial theory into the field of eighteenth-century studies has generally left Enlightenment relatively untouched" (2009: 2). The process of freedom and emancipation declared by enlightenment are currently undermined as Western projects, sources of exploitation and essentially anti-diversity and ideological in creating the other as illogical and emotive. Hence, "In as much as its values are identified as coextensive with modernity, the Enlightenment naturalizes a teleology in which all roads lead inexorably to an episteme associated with the West" (Ibid: 8). Thus whether conceived in terms of Habermas' unfinished project of modernity or the farewell to enlightenment in the postmodern critique of reason, critical theory did not recognize the relation between enlightenment and colonialism as well as the creation of the other as the other side of enlightenment.

\section{Value Incommensurability as a challenge to Intercultural Philosophy and Critical Theory}

The approaches of intercultural philosophy and critical theory are founded on a quasi-transcendental methodology that identifies the underlying presuppositions of the embedded nature of human cognition and everyday praxis. Specifically in Habermas, one finds an approach that revolves between idealizing presuppositions 
and fallibility approach, universality of validity claims and everyday speech acts. This still leaves out the question, how does one reconcile different grounds of critique, life worlds, horizons of meaning and spaces for emancipatory praxis? The challenge of incommensurability was introduced by Thomas Kuhn as a way of situating the logical outcomes of scientific revolutions and the change of paradigms. Kuhn situated incommensurability as the fact that semantic difficulties complicate translation amongst paradigms. Kuhn argues, "the claim that two theories are incommensurable is then the claim that there is no language, neutral or otherwise, into which both theories, conceived as sets of sentences, can be translated without residue or loss" (1982: 670). Kuhn's thesis of incommensurability could be analyzed methodologically in terms of the lack of a common standard amongst paradigms, perceptually in terms of scientists within paradigms experiencing the world in different terms and semantically in terms of using different language across paradigms. It is semantic incommensurability that lays the foundation for value incommensurability or values within paradigms being incomparable with one another.

The idea of incommensurability in intercultural communication and the social realm refers to the fact that the meanings in texts are always deferred, no common universe of discourse exists, interpretation is always embedded and seeking an objective stance amounts to a forceful imposition on others. Accordingly, "incommensurability refers to a state in which two phenomena (or worlds) cannot be compared by a third without producing serious distortion" (Povineli 2001: 320). The thesis of incommensurability and its effect on common discourse is also identified by linguistic anthropologists who focus on the nature of grammar and sociologists who identified the act of commensuration as one that is potentially detrimental to the diversity of worldviews and also individual autonomy since meaning is forcefully imposed structurally to arrive at such consensus. One as such needs to ask, "What are commensuration's practical and political effects? What are the tensions between ethical systems and the formal rationality of commensuration" (Ibid: 325).

Sankey (1991) argues that the analysis of semantic incommensurability is dictated by the background meaning on one side and the quest for a shared meaning that is limited by local worlds of meaning on the other. In such a context, "Since comparison must take place in some language, the question arises in which language theories which fail to be inter-translatable may be compared" (Ibid: 415). Sankey further claims that the thesis of semantic incommensurability could be expressed in the difference between translation as an act of expressing the cognitive context of one language in another and understanding as the connection between an individual member of a language and the language itself. Thus, "to understand something said in a language is to know what it means and to arrive at knowledge of the meaning of an utterance requires a minimal competence in the 
language" (Ibid: 417). Specifically, Raz assumes that the viability of the incommensurability of values should be explained in terms identifying the difference between the equality of all cultures and values vs. their incommensurability. Accordingly, "one must give it an interpretation which explains in what way incommensurability differs from equality of value" (1985: 119)

Our representations, frames, worldviews and backgrounds limit discourse and aims at mutual cooperation. Here, "the question is how we talk about culturally significant issues across such differences?" (Flower 2003: 39). Flower's analysis of intercultural rhetoric further reveals that such attempts at communication embody both existing practices of individuals as well as societal dynamism, cultural values, ideological presuppositions and ontological foundations. For the existence of an intercultural encounter, shared worlds and a public sphere that equally accommodates diverging voices must be founded, although, "the practice of rhetoric has been historically identified with analogues to the Greek polis, a restricted, homogenous body of peers (that excluded women, foreigners, and slaves)" (Ibid: 43).

\section{Multiple Modernities as an alternative model for the Inclusion of the Other} Going beyond the charges of eurocentrism and incommensurability, I think the approaches of intercultural philosophy and critical theory need to incorporate the notion of multiple modernities as an alternative model for the interpretation of critique, emancipation and otherness in different cultural centers of the world.

Discontent with Western narratives of modernity and attempts to find a space for multiple horizons of modernity led into the inception of multiple modernities. Thus, "the theory of multiple modernities has been developed out of a deep sense of frustration with the conventional or classical theories of modernization which, in some scholars' eyes, have failed to explain the diversity of modern societies found across the globe, especially in the second half of the twentieth century"(Ichijo 2013: 27-28). The idea of multiple modernities conceives modernity as emerging in a particular cultural, social, political and institutional framework. The conception also does not necessarily assume that diverse modern projects will converge on a historical path. Thus, "the core of multiple modernities lies in assuming the existence of culturally specific forms of modernity shaped by distinct cultural heritages and sociopolitical conditions"(Eisenstadt et al. 2002: 1). Starting from the year 2000 and the appearance of the notion of multiple modernities in the Journal of the American Academy of Arts and Sciences, one witnesses a wide usage of the term in the analysis of modernity and discussions in the social sciences.

For Eisenstadt, the world of globalization does not constitute the emergence of modernity in a global scale, conflicts among ideologies or a zeal for the past. On 
the contrary, one witnesses attempts to reground the project of modernity in different soils and cultural programs. As such, "all these developments and trends constitute aspects of the continual reinterpretation, reconstruction of the cultural program of modernity" (2003: 517). The essence of modernity lies not in the continuation of the past, cumulative history or future utopian thinking but a radical departure and a civilization perspective and as such, "of a distinct social "imaginaire," indeed of the ontological vision, of a distinct cultural program, combined with the development of a set or sets of new institutional formations" (Ibid:493). Eisenstadt further observes that western modernity encompassed both ideological and institutional programs. The former resides in the dissemination of Western cultural constructs in different corners of the world and the latter in constituting a system of administration over the different corners of the world. Rather than simply situating different cultural programs as Westernization in different contexts, one witnesses the advent of multiple modernities. This constitutes modern projects informed by respective backgrounds; diverging ways of understanding what it means to be modern and introducing cultural programs as the main forces in the quest for modernity.

Intercultural philosophy's quest for widening the space of intercultural participation and critical theory's attempt to introduce both a critical and emancipatory practice could learn from the alternative model of multiple modernities in the following ways. The notion of multiple modernities goes beyond the modern vs. traditional dichotomy that the emancipatory models of critical theory operate within since it assumes that modernity is culturally oriented. It assumes that every culture aspires for novelty, progress and refinement in the world of other cultures and alternative ways of being. Rather than positing a universal path of rationalization that all cultures must go through, it assumes that every culture represents a unique vision of modernity. This shows that all attempts to evolve a model of emancipation should recognize the unique aspects of every cultural location and cognitive horizons.

The approach of multiple modernities does not manufacture an other, a self and an identity that is the other of the enlightened west. Rather than creating false identities that negate the western self, it sees all cultures in a parallel representing diverse ways of interpreting modernity. It sees modernity as a quest that receives inputs from diverse spatio-temporal locations. This helps to initiate comparative studies among different interpretations of modernity. Multiple modernities as an alternative model sees the world of knowledge production as taking place in different sites of knowledge. Rather than seeing the fate of humanity as being driven by a universal logic of materialistic production, it affirms the existence of diverse ways of relating to the human and natural worlds. It treats incommensurability as an essential feature of different interpretations of modernity 
and human progress, rather than trying to develop an objective ground for human emancipation.

\section{Conclusion}

The paper tried to critically expose the discourse on critique, emancipation and otherness as viewed from the perspectives of intercultural philosophy and critical theory. Intercultural philosophy resists ethnocentrism and centrism in the process of cultural encounters. This is based on the exposure of grand claims to truth, which yield hierarchical relations amongst cultures. Whereas expansive, integrative and separative centrisms added to a reductive hermeneutics conceptually negate the other and practically enslave other cultures; the solution lies in situating truth as a dialogical search residing in both the objective and relative aspects of the human experience. Critical theory also exhibits a critique of absolutist metaphysical claims and grand narratives that negated the potentials for emancipatory critique in everyday horizons of meaning. It also introduces models of emancipation that focus on exposing of contradictions, limitations of technical progress and the praxis of the sciences.

The analysis subsequently revealed that both approaches fail to transcend the eurocentrism of the modern project and the incommensurability of values. In the quest for the other, comparative ventures and affirming the existence of philosophy in different cultural contexts, intercultural philosophy creates the other in a system of binary oppositions. Critical theory also fails to deconstruct the eurocentrism of modernity and introduces its analysis only on the contradictions of instrumental rationality and modern progress within the Western context. The failure of both intercultural philosophy and critical theory to overcome value incommensurability paves the ground for the exploration of multiple modernities within diverse cultural contexts of the world which are found in a parallel horizon all striving for novelty. In multiple modernities the issue of otherness disappears since all partners in the discourse of modernity equally strive for perfection and progress. Abandoning the linear progression of history and the binary opposition between the West and the other, modernity is situated in different projects of emancipation. 


\section{References}

Agadjanian, Victor. 2008. "Research on International Migration within SubSaharan Africa: Foci, Approaches, and Challenges". The Sociological Quarterly, 49(3): 407- 421.

Antonio, Robert J. 1983. "The Origin, Development and Contemporary Status of Critical Theory". The Sociological Quarterly. 24(3): 325-351.

Beck, U., Adam, B and Loon, J. 2005. The Risk Society and Beyond: Critical issues for Social Theory. UK: Sage Publications.

Bekele, Gutema. 2015. "The Intercultural Dimension of African Philosophy". African Study Monographs 36(3): 139-154.

Blocker, Gene. 1999. World Philosophy: An East-West Comparative Introduction to Philosophy. USA, New Jersey.

Bronner, Stephen Eric. 2011. Critical Theory: A Very Short Introduction.USA: Oxford.

Festa, Land Carey, D. 2009. The Postcolonial Enlightenment: Eighteenth Century Colonialism and Postcolonial Theory. U.S.A: Oxford.

Delanty, Gerard. 2009. The Cosmopolitan Imagination; The Renewal of Critical Social Theory. UK: Cambridge.

Eisenstadt, S N., Sachsenmaier, D. and Riedel, J. 2002. Reflections on Multiple Modernities: European, Chinese and Other Interpretations. UK: Leiden.

Eisenstadt, S.N. 2003. Comparative Civilizations and Multiple Modernities. UK: Leiden.

Epstein, G. and Gang, I. 2010. Migration and Culture. UK: Emerald Group Publishing.

Feenberg, Andrew. 1981. Lukas, Marx and the Sources of Critical Theory. USA: Rowman and Littlefield.

Ferrara, Alessandro. 2002. Reflective Authenticity: Rethinking the Project of Modernity. UK, London.

Flower, Linda. 2003. "Talking across Difference: Intercultural Rhetoric and the Search for Situated Knowledge". College Composition and Communication 55(1): 38-68.

Flynn, Jeffrey. 2003. "Habermas on Human Rights: Law, Morality, and Intercultural Dialogue". Social Theory and Practice 29(1): 431-457.

Giddens, Anthony. 1996.The Consequences of Modernity. UK: Cambridge.

Habermas, Jürgen. 1987. The Philosophical Discourse of Modernity, Twelve Lectures. Translated by Frederick Lawrence. USA: Massachusetts.

Habermas, Jürgen. 1998. The Inclusion of the Other: Studies in Political Theory. USA: The MIT Press.

Harvey, David. 1992. The Condition of Postmodernity: An Enquiry into the Origins of Cultural Change. USA: New Jersey. 
Horkheimer, Max. 2002. Critical Theory: Selected Essays. Translated by Matthew J. O' Connell. USA: Continuum.

How, Alan. 2003. Critical Theory. UK, London.

Hoy, D C. and McCarthy, T. 1994. Critical Theory. UK: London

Chen, Hsueh-I. 2010. "The Concept of the "Polylogue" and the question of "Intercultural" Identity". Intercultural Communication Studies, 19(3): 54-64.

Hoy, David Couzens and McCarthy, Thomas. 1994.Critical Theory. U.S.A: Massachusetts.

Ichijo, Atsuko. 2013. Nationalism and Multiple Modernities, Europe and Beyond. UK: Palgrave Macmillan.

Kaltenbacher, Wolfgang. 2011. "Beyond the Cultural Turn: Intercultural Philosophy in its Historical Context". In Sweet, W. editor. What is Intercultural Philosophy? USA: Washington, D. C.

Kellner, Douglas. 2001. Towards a Critical Theory of Society: Collected papers of Herbert Marcuse. UK: London.

Kuhn, Thomas. 1982. "Commensurability, Comparability, Communicability". Proceedings of the Biennial Meeting of the Philosophy of Science Association, 2(1):669-688.

Lipner, Julius J. 1993. "Seeking others in their Otherness" New Blackfriars, 74(869): 152-165.

Liu, Wei, 2013. "Exploration of the Intercultural". Journal of Modern Literature, 37(1): 194-195.

Lyotard, Jean-Francois. 1984. The Postmodern Condition: A Report on Knowledge. UK: Manchester.

Mall, Ram A. 2000. Intercultural Philosophy. U.S.A: Maryland.

Marcuse, Herbert. 1974. Eros and Civilization: A Philosophical Inquiry into Freud. USA: Boston.

Martinez, Celeste. 2015. "Otherness and the Nature of the Multifaceted Self". Res Cogitans 6(1): 5-29.

McGhee, Michael. 2011. "The Philosopher as Stranger: The Idea of Comparative Philosophy”. In Joy, Morny .editor. After Appropriation: Explorations In Intercultural Philosophy and Religion. Canada: Alberta.

Monaghan, Leila. 2012. "Perspectives on Intercultural Discourse and Communication". In Christina B., Paulston, S F., and Elizabeth S. R. The Handbook of Intercultural Discourse and Communication. U.S.A: New Jersey.

Olu-Jacob, D. 2014. "Interculturality in the Context of Africa's Colonial and Decolonization Experience". In Sweet, William, Editors. What is Intercultural Philosophy? USA: Washington, D. C. 
O. Schrag, Calvin. 2006. "Otherness and the Problem of Evil: How Does That Which Is Other Become Evil?" International Journal for Philosophy of Religion 60(1): 149- 156.

Ozoliņ̌s , Jānis T. 2013. "What in the World is Intercultural Philosophy? A Reflection". In Sweet, William, editor. What is Intercultural Philosophy? USA: The Council for Research in Values and Philosophy.

Passerin, M and Benhabib, S. 1997. Habermas and the Unfinished Project of Modernity: Critical Essays on The Philosophical Discourse of Modernity.USA: The MIT Press.

Paulston, C., Bratt. K., Scott F. and Rangel E. 2012. The Handbook of Intercultural Discourse and Communication. USA: New Jersey.

Pels, Peter. 1997. "The Anthropology of Colonialism, Culture, History and the emergence of Western Governmentality". Annual Review of Anthropology 26(1): 163-183.

Piccone, Paul. 1976. "From Tragedy to Farce: The Return of Critical Theory" New German Critique, 7(1): 91-104.

Povinelli, Elizabeth A. 2001. "Radical Worlds: The Anthropology of Incommensurability and Inconceivability". Annual Review of Anthropology, 30(1): 319-334.

Raz, Joseph.1985. "Value Incommensurability: Some Preliminaries" Proceedings of the Aristotelian Society New Series, 86(1): 117-134.

Rüsen, Jörn .2004. "How to Overcome Ethnocentrism: Approaches to a Culture of Recognition by History in the Twenty-First Century". History and Theory, 43(4): 118-129.

Rush, Fred. 2004. "Conceptual foundations of early Critical Theory" In Rush, Fred, Editor. The Cambridge Companion to Critical Theory. U.S.A: University of Notre Dame Press.

Sankey, Howard. 1991. "Incommensurability, Translation and Understanding" The Philosophical Quarterly, 41(165): 414-426.

Shen, Vincent. 2011. "Comparative Studies in Philosophy/Religion and Dialogue asMutual "Strangification". In Joy, Morny, editor. After Appropriation: Explorations In Intercultural Philosophy and Religion. Canada: Alberta.

Sheperd, Nick. 2002. "The Politics of Archaeology in Africa". Annual review of Anthropology 31(1): 189-209.

Solimano, Andrés. 2010. International Migration in the Age of Crisis and Globalization: Historical and Recent Experiences. USA: Cambridge.

Staszak, J.F. 2009. "Other/Otherness", In Kitchin R. and Thrift N., editors. International Encyclopedia of Human Geography, 8(1): 43-47.

Steunebrink, G. and Zweerde, E. Van Der. 2004. Modernization in Intercultural Context: Russia, Japan, Turkey. USA: Amsterdam. 
Sweet, William. 2014. "The Project of Intercultural Philosophy", In Sweet, William, editor. What is Intercultural Philosophy? USA: The Council for Research in Values and Philosophy.

Thomassen, Lasse. 2006. "The Inclusion of the Other? Habermas and the Paradox of Tolerance." Political Theory, 34(4): 439-462.

Treanor, Brian. 2006. Aspects of Alterity: Levinas, Marcel, and the Contemporary Debate. USA: New York.

Wimmer, Franz Martin. 2002. Essays on Intercultural Philosophy. India: Chennai. 